\title{
Sociocultural Determinants of Alcohol Abuse by Youths in Luanda Sub-county, Vihiga County, Kenya
}

\author{
Clifford M. Matara \\ Department of Public Health, Maseno University, Kenya \\ Maureen A. Winga \\ Department of Education Psychology, Maseno University, Kenya
}

Doi:10.19044/esj.2021.v17n14p121

Submitted: 19 February 2021

Accepted: 21 April 2021

Published: 30 April 2021
Copyright 2021 Author(s)

Under Creative Commons BY-NC-ND

4.0 OPEN ACCESS

Cite As:

Matara C.M. \& Winga M.A. (2021). Sociocultural Determinants of Alcohol Abuse by Youths in Luanda Sub-county, Vihiga County, Kenya. European Scientific Journal, ESJ, 17(14), 121. https://doi.org/10.19044/esj.2021.v17n14p121

\section{Abstract}

The WHO (2014a) indicates that 3.3 million deaths (5.9\%) of all global deaths annually are attributable to alcohol abuse; with $5.1 \%$ of the global burden of disease and injury attributable to alcohol abuse. Alcohol is the most abused substance with the most affected persons being youth. In Kenya, prevalence of alcohol abuse by youths aged 18 -35 years was $17.6 \%$ against the national average of the general populace which is at $13.6 \%$. In the year 2017 Luanda sub-county recorded 635 reported cases of alcohol abuse with the administrators. Of the 635 reported cases in Luanda, 71 (11.18\%) cases were of under 18 years, 192 (30.24\%) were elderly (above 35 years) while 372 (58.58\%) were aged 18-35 years. The objective of this study was to assess parental, peer, spousal and cultural influences of alcohol abuse by youths in Luanda Sub-county. A total of 422 respondents derived using Fischer's formula were involved. Multi-stage sampling was done at sub-locations, villages and households to obtain respondents. Questionnaires featuring Audit tool score and Focus Group Discussions were used to collect data. Odds ratio with $95 \%$ confidence interval was employed to determine the likelihood of alcohol abuse. Qualitative data was analyzed using content analysis method. The socio-cultural factors associated with alcohol abuse were: parental alcohol use $(p=0.000)$, peer influence ( $p=0.000)$, spousal alcohol use $(p=0.035)$. The multivariate analysis showed significant association between alcohol abuse 
and spousal alcohol use ( $\mathrm{p}=0.035 \mathrm{OR}=0.462[0.223-0.955])$, parental use of alcohol $\quad(p=0.000 \quad O R=28.667 \quad[15.516-52.965])$ and peers $\quad(p=0.000$ $\mathrm{OR}=10.012$ [3.424-29.273]).

Keywords: Social, Cultural, Alcohol Abuse, Youth, Kenya

\section{Introduction}

The World Health Organization (WHO, 2014) indicates that 3.3 million deaths or $5.9 \%$ of all global deaths annually are attributable to alcohol abuse. The WHO (2014) further indicates that the global burden of disease and injury attributable to alcohol abuse stands at $5.1 \%$. Alcohol consumption relates to more than 200 health conditions. New studies have given data on causal relationships between alcohol abuse and the incidence and clinical outcomes of infectious diseases including tuberculosis, HIV/AIDS and pneumonia. Besides, alcohol is associated with social, economic, mental and emotional issues expressed as absenteeism or abuses in social institutions such as workplaces and relationships. Non-consumers of alcohol have often become victims of alcohol related incidences.

Youths are defined by the United Nations as young people between the ages of 15-24 years of age (United Nations, 2015). This is purely for statistical purposes without prejudice to other definitions by Member States. The Government of Kenya defines 'youth' as any person between the ages of 1835 in its Kenya National Youth Policy (Government of Kenya [GOK], 2006). Seventy-five per cent of the Kenyan population are aged 30 years and below (Kenya National Bureau of Statistics [KNBS], 2017). According to the National Agency for the Campaign against Drug Abuse [NACADA] (2012), Alcohol is the most abused substance in Kenya. Current abuse of alcohol in Kenya among persons aged $18-35$ years is $17.6 \%$ against the national average of the general populace which is at $13.6 \%$; with the urban youthful population abusing alcohol more frequently (17.0\%) compared to the rural youthful population $(11.8 \%)$. Moreover, more males abuse alcohol than females. NACADA (2012) also indicates that the Western Region of Kenya aggregate of sub-counties including Luanda reported current usage of $10.2 \%$ of alcohol within the population. However, a study done in Kakemega County by Takahashi, Wilunda, Karani, Wilunda and Useneya (2017) set the prevalence of alcohol abuse at $31.7 \%$. The report alludes to under reporting of prevalence rates by a Kenyan government agency, NACADA, and proximity of the Western region to the republic of Uganda, which has a prevalence of $28.6 \%$. It also infers to the shared ethnic and cultural backgrounds between Western Kenya and Uganda including trends of alcohol abuse. 
Thus, while there may be several factors that may cause alcohol abuse such as genetics, presence or absence of social support networks and access and use of health services, the development of alcohol abuse tendencies is largely dependent on social and environmental factors. There are a number of sociocultural factors that have direct influence on alcohol abuse among the youths. A study conducted by Osei-Bunsu et al. (2017) among Youths in Ghana indicates that the major factors contributing to the abuse of alcohol are peer influence and advertisement. Religion and occupation were also other factors found to be strongly associated with alcohol abuse. Another study in Nepal, India, found the association of alcohol abuse to be highly significant with age-group, gender, ethnicity, family and friend's history of alcohol abuse (Maharjan and Magar, 2017). However, other published studies such as Ndegwa et al. (2013) among youths in Daystar University, found out that ever seeing the mother abuse alcohol had marginal significant association with alcohol intake by the respondent. Takahashi et al. (2017) in Ikolomani, Western Kenya it was found out that education was statistically not significantly associated with alcohol abuse. However, this study was conducted among the general populace of ages 15 to 65 years. The socio-cultural factors which resonate with alcohol abuse among youths in Luanda Sub-county remain unclear. From various studies such as Ndegwa et. al (2013), Osei-Bunsu et. al. (2017), Takahashi et. al. (2017), there are many attributes of the socio-cultural factors that are likely to influence alcohol abuse among the youth. However, major focus will be given on the attributes that have shown correlation to alcohol abuse among the youth in other places or whose relation to alcohol abuse among youth has not been exhaustively settled. From Ndegwa et al. (2013), Osei-Bunsu et al. (2017), White, Johnson and Buyske (2000), Parental alcohol abuse and Peer Influence have been shown to have an influence on alcohol abuse and are thus included for this study. Customs differ in the outcome of alcohol abuse among youths in various studies andwill be assessed in this study.

Studies by Osei-Bunsu et al., 2017; Ndegwa et al., 2013; Michuki, 2014 and Okwarah, 2017 carried out under the theme of alcohol abuse by youths did not give detailed insights on determinants of alcohol abuse among youths. These studies focused on youth in secondary schools or tertiary institutions and do not give an account for out of school and jobless youths who make a significant segment of the Kenyan population today and in Luanda sub-county. Equally, these studies have focused on sections of youths such as 15-24 years, 18-25 years without considering the whole youthful bracket of 18-35 years as envisioned by the Kenyan people through the Constitution of Kenya. Although these studies attained their objectives, they did not delve into determinants of critical factors such as spousal effects among other factors due to inherent limitation of age-bracket or the demographical factors such as schooling where some factors such as marital status and its influence are often conspicuously absent. It is against this background that the current study will be undertaken. 
This study will therefore assess the sociocultural determinants of alcohol abuse among youths in Luanda sub-county, Vihiga County, Kenya.

\section{Statement of the problem}

While there is much information on determinants of alcohol abuse on youth who are found at household levels such as those in schools, colleges and organized groups such as bodaboda riders, there is scanty information on nonschooling and jobless youth. Some age brackets of the youth who are found at household levels such as the married group have been excluded from previous studies making it difficult to get a holistic picture on the actual determinants of alcohol abuse among the youth in society and in Luanda sub-county in particular. Measures to reduce alcohol abuse are largely informed by understanding the determinants of alcohol abuse in a given region and Luanda sub-county is no exception. In order to put in place measures to reduce alcohol abuse in Luanda sub-county, the precise social and cultural factors influencing alcohol abuse will have to be determined vis-à-vis extrapolating other regions' factors to the sub-county.

\subsection{Socio-cultural factors influencing alcohol abuse by youths in households}

\subsection{Parental alcohol consumption}

A considerable amount of research has examined the impact of parental alcohol consumption on children's development. The research reveals that children can and do suffer from a range of maladaptive outcomes spanning all areas of development, including the cognitive, behavioural, psychological, emotional and social domains (Grekin, Brennan \& Hammen, 2005). Children reported feeling socially excluded, frequently being left alone, having a sense of not being loved, and having feelings of low self-worth. They also took on responsibility for caring for their parent/s. (Grekin et al.,2005)

According to Donovan \& Molina (2014) consistent risk factors for adolescent youth drinking are youths' perception that parents approve of their alcohol or drug abuse, parent or older sibling alcohol abuse tendencies.Most research now supports explanatory models in which the outcomes for children are not only dependent on parental alcohol dependence but on the aggregation of factors such as individual characteristics, family interaction, and the psychological functioning of both parents.

Mwai, Wamue and Mwangi (2013) observe that adult children of alcoholic parents have lower self esteem and increased likelihood of becoming alcoholics. Sirera and Mwenje (2014), further points out that lack of close interaction with the children makes parents who abuse alcohol to miss out on many opportunities that would enable them guide the children thus predispose them to secondary role models, who are often peers and who can lead the children to alcohol and drug abuse. 
Further NACADA (2012) argue that excessive alcohol abuse, leading to addiction, depletes family finances leading to poverty and inability to meet family obligations including paying school fees, purchase of food and other amenities. These psychosocial depressors then become a predisposing factor towards alcohol abuse by the younger generation (Ndakalu, 2014).

Researchers have identified a strong correlation between parental and children's drinking behavior over the life-course suggesting that children tend to model the drinking patterns and styles of their parents (White, et al., 2000). In contrast, other research illustrates an association between parents who abstain and children who become heavy drinkers in later life (Roche, 2001). This suggests that not only are the relationships between parental influences and children's outcomes complex but also that imitation of parents is not a sufficient explanation of how young people learn to abuse alcohol.

In a published study done among students in Daystar University in Kenya by Ndegwa et al (2013), ever seeing the mother abuse alcohol had marginal significant association with alcohol intake scores. Contrary to expectation, never seeing the mother abuse alcohol was significantly associated with higher mean alcohol intake scores of $28.4 \%$ compared to ever seeing mother abuse alcohol which stood at $22.3 \%$. This indicated that those who had not seen their mothers abuse alcohol ended up with a higher mean alcohol intake score compared to those who had ever seen the mother abuse.

The aforementioned studies on parental alcohol use and effect on their childrens' use are inconclusive. There is need to find out whether parental alcohol abuse leads to abuse of alcohol in the children or not. This is especially so in Luanda sub-county in Western Kenya.

\subsection{Spousal alcohol consumption}

With respect to spouses, divorced and widowed men (those without spouses) tend to abuse alcohol the most (O'Connel et al., 2013). Risk factors for alcohol dependence among young people include being divorced, separated or never married (Grekin et al., 2005; Schemied and Montrose 2006).

Kenneth et al. (2018) shows that the risk of alcohol abuse of a person increases when a person's spouse has an alcohol use disorder and decreases when the partner did not have an alcohol use disorder. Robles and KieclotGlaser (2003) argue that marriage, even among alcohol users, is associated with better health and that unmarried persons are more likely to engage in unhealthy behaviors such as smoking, heavier alcohol consumption and poor diet. A study done in Tanzania by Francis et al. (2015) showed that being in a relationship, with either an alcohol consuming spouse or not, was associated with alcohol abuse. 


\subsection{Peer Influence}

In Uganda, in a study by Kanyesigye, Basiraha, Ampaire, Wabwire, Waniaye, and Kangi (2000) it was noted that among the youths, 19\% of the secondary school students and about $35 \%$ of the students in tertiary institutions abused drugs including alcohol. From the study, this was attributed to a lot of alcohol products being advertised in relation to style/fashion; and due to peer influence.

In a study carried out by Takahashi et. al (2017) in Ikolomani Subcounty, Kenya in 2015, it was found that the number of alcohol consumers in the family and the number of friends who drink showed statistically significant associations with alcohol drinking. The number of drinkers in the family had the strongest effect on current alcohol abuse followed by the number of friends who drink alcohol. Participants with more than one drinker in the family had more than a 35-fold increase in the odds of alcohol intake compared with those who did not have any drinker in the family. This study was carried out in a rural setup in western Kenya for age-groups 15-65 years.

A study carried out by Ngesu, Ndiku, and Masese (2008) on drug dependency and abuse in Kenya secondary schools in Kisumu municipality showed availability of drugs, peer group pressure, age factor among peers, curiosity by peer, availability of cash among peers and high handedness of school administrators were to blame for drug abuse.In the present study, peer influence was investigated in specific reference to alcohol consumption among youth aged 18-35.

\subsubsection{Cultural Practices when Alcohol is abused}

In a study in Northern European countries it was found out that a cultural practice to the pursuit of drunkenness and seeking intoxication only in the company of others (group intoxication) had developed. Respondents were also aware of wider cultural ideas, 'handed down', that alcohol could be used to deal with problems and relieve stress (Seaman and Ikegwuonu 2010).

In a study to establish the Maasai community perception on alcohol abuse among students, (59.2\%) of the respondents said that cultural beliefs and practices advance usage of alcohol by students. (80\%) of the teachers indicated initiation ceremonies as the main cultural practice that advance usage of alcohol by students in Maasai community $45.7 \%$ implied that availability of alcoholic beverages in cultural ceremonies encourages students to consume alcohol (Keiwua 2016). NACADA (2007) also found out that the decision to drink by both adults and young people is motivated by a variety of factors, such as cultural acceptability of alcohol.

Some cultures recommend taking of depressants such as beer, liquor, wine and cannabis sativa during cultural functions(Ambale, 2015). Some liquor such as busaa or drugs such as miraa are culturally accepted and during these cultural ceremonies or festivities, people are grouped in age sets and provided 
with the drugs (Ambale, 2015). Given that the Wanyore of Luanda sub-county conduct cultural circumcision, burial and wedding ceremonies, the present study investigated the influence of customs on alcohol abuse.

\section{Research Methodology}

\subsection{Study Site}

The study was conducted in Luanda sub-county in Vihiga County, Kenya. Vihiga County is located in Western Kenya. The county experiences high equatorial climate with well distributed rainfall throughout the year. Temperatures in the region range between $14^{\circ} \mathrm{C}-32^{\circ} \mathrm{C}$ and subsistence agriculture is the main economic activity (County Government of Vihiga CIDP, 2013).In the year 2017 authorities in Luanda sub-county recorded 635 reported cases of alcohol abuse compared to 524 in Emuhaya sub-county and 491 in Hamisi sub-county. According to the population and housing census (KNBS 2009) Luanda Sub-County was projected to have 25,310 households with a population of 53,621 aged between 18-35 out of the total 113,029 persons in the sub-county.

\subsection{Research Design}

A cross-sectional research design was used in the study. This enabled collection of information from a large sample over a short period of time. Piloting of the study tools was done on $24^{\text {th }}$ June $-1^{\text {st }}$ June 2019 and the tools retested on $2^{\text {nd }}$ July 2019 and $5^{\text {th }}$ July 2019 after incorporating changes. The actual study was conducted from $8^{\text {th }}$ July 2019 to $30^{\text {th }}$ July 2019 in a total of 20 days.

\subsection{Research variables Independent variables}

Socio-cultural factors

Among social-cultural factors, the variables assessed in the study were peer influence, spousal alcohol use, parental alcohol use and customs.

\section{Dependent variable}

Alcohol Abuse

The dependent variable was the level of alcohol abuse. The respondents (youths aged 18-35 years) were classified into five categories: no risk, low risk, hazardous level, harmful level and high risk depending on the Alcohol Use Disorder Identification Test (AUDIT). No risk and Low risk indicated no alcohol abuse while the three latter classifications, which have an AUDIT score of 8 or more were indication of Alcohol Abuse (WHO, 2001). 


\subsection{Target population}

The study was conducted among youths living in households in Luanda Sub-County. According to the population and housing census (KNBS 2009) Luanda Sub-County was projected to have 25,310 households with a population of 53,621 aged between 18-35.

\subsection{Sampling design}

\subsection{Sample size determination}

Sample size was determined using the single population proportion formula as used in Fischer et al, 1977. This gave a provisional size of 384 people as the minimum number of individuals necessary or the study.

An additional 10\% was added to bring the final sample size to 422 in order to estimate the study outcome to within $\pm 0.5 \%$, allowing for sampling defect. This covered for unexpected attrition. Since the target population was more than 10,000, that is 25,310 households (KNBS, 2009) there was no need for further adjustment to the sample size.

\subsection{Sampling procedure}

Multi-stage random sampling was applied in the study since no complete list of households with youths was available for Luanda sub-county. The process of multi-stage sampling involved selection of sub-locations, villages and households to yield individual youths in the household -using the ballot system. Selection of 10-sublocations from the 29 sub-location in Luanda sub-county involved printing a list of all the sub-locations. a piece from the stock to make a sample of 10; which was returned before the next pick to ensure there is equal chances of each sub-location to be picked .All 10 sub-locations picked had their villages printed and the random balloting was done to pick one-third of the villages in each sub-location. Next the households were listed in a geo-spatial manner and the random picking occurred to select the households to participate. Two Focus Group Discussions (FGDs) were held comprising of seven members each. To get the members for the FGDs, the researcher identified and selected from the villages randomly during questionnaire administration members who willingly identified themselves during introduction of questionnaire administration as members of such a group as bodaboda rider, religious youth leader, administrative (county, sub-county, village, chama) youth leader, university/college student, social mobilizer, farmers, high school students, traders, artisan or driver and who on request acknowledged to be available and willing to participate in the FGD. The investigator, thus engaged the members and purposively selected those who would provide the required information with respect to the objectives of the study. No two or more people from the same cadre were in a similar FGD and care was taken to ensure the persons came from as diverse geospatial sub-locations as possible. This was done in a manner that no two respondents within an FGD came from the same sub-location. 


\subsection{Inclusion and exclusion criteria}

\subsubsection{Inclusion criteria}

i. Individuals aged $18-35$ years .

ii. Residents of Luanda Sub-county for the last 1 year.

iii. Those who gave written consent were included in the study.

\subsubsection{Exclusion Criteria}

i. Residents of Luanda sub-county but who are non-Kenyans.

ii. Respondents who were intoxicated during the time of the study were excluded due to reliability and consistency in their responses.

iii. Those who declined to give written informal consent despite meeting other conditions.

\subsection{Data Collection tool}

Two instruments were used to collect data in this study. These were questionnaires and focus group discussions.

\subsubsection{Questionnaires}

The principal investigator was assisted by four individuals, who were trained on basic research on administering the questionnaires. A pretested questionnaire was administered in either English, Swahili and the dialect of Luhya language spoken in the local area, Kinyore, to the member of the household after obtaining informed consent.

\subsubsection{Focus group discussions}

The investigator organized two focus group discussions from among the youths in the various sub-locations in the sub-county. The FGDs were moderated by the principal investigator. The individual responses for focus group discussions were captured both electronically and in writing.

\subsection{Pretesting of data collection tools}

To achieve reliability, test re-test of the questionnaire was conducted on the same 39 respondents who were not included in the final study, within a 2 weeks interval. Data collected in this pilot test was analyzed using SPSS. A correlation coefficient $(r)$ of 0.87 was established.

To maximize on validity, AUDIT test which is recommended by WHO for alcohol abuse measurements because it has been tested and validated in several populations, races and ethnicities was used. Content validity was also achieved by a rational analysis of the instrument by the co -investigators /supervisors who are familiar with substance abuse and by extension, experts on the research subject. Adjustments were made on the data collection tools according to the findings of the pretest. Comments made by respondents were incorporated into the final questionnaire. 


\subsection{Data analysis and presentation}

Data was analyzed using Statistical Package for Social Sciences (SPSS) (version 20).

To enable study findings on each question to be fully described, descriptive statistics were analyzed in terms of frequency, percentages and means for socio-demographic factors.

Cross-tabulation using chi square was used to determine the association between the dependent and independent variables. The strength of association of alcohol abuse and socio-cultural factors was assessed using odds ratio measures. Responses from Focus Group Discussions were analyzed using content analysis and summarized into emerging themes.

\subsection{Ethical consideration}

The proposal for the study was presented to Maseno University Ethics Review committee (MUERC) and National Commission for Science, Technology and Innovation (NACOSTI) for scientific review and ethical approval. Permission to collect data was sought from Vihiga County Director of Public Health and Sanitation. To ensure confidentiality, questionnaires were numbered serially and no names were written by the respondent. Data generated was held confidentially by the principal investigator by use of a safe locker and was used for purpose of the research only. Security codes were assigned for all computerized records such as digitally captured discussions. Participants in need of medical/counseling attention were referred to public health institutions in Vihiga County.

\section{Results and Discussions}

\subsection{Socio-demographic characteristics of respondents}

Most of the respondents 260 (64.2\%) were male while 145 (35.8\%) were female. Furthermore, 261 (64.44\%) respondents were single while $143(35.31 \%)$ were married.

A total of $153(37.8 \%)$ respondents aged between 24-26 were the highest in number, followed by those aged 27-30 who were 91 (22.5\%). Only 45 $(11.1 \%)$ of the respondents were between 18-20 years. The average age of the respondent was $25.65 \pm 1.650$ years. With regards to educational attainment, slightly half $213(52.6 \%)$ had secondary school level of education while 17 (4.2\%) had never attained any level of education.

\subsection{Socio-cultural factors associated with alcohol abuse among youths in Luanda Sub-County}

\subsubsection{Parental alcohol use}

A total of 168 respondents indicated that their parents abused alcohol. Of these, 112 (66.7\%) abuse alcohol while 56 (33.3\%) do not abuse alcohol. A bivariate analysis shows a strong relationship between parental alcohol use and 
the respondents alcohol abuse. Those with alcohol using parents are 28.667 times likely to abuse alcohol than those whose parents did not abuse alcohol $(\mathrm{OR}=28.667, \mathrm{CI}=95 \%[15.516-52.965])$.In this study a significant association between alcohol abuse and parental alcohol consumption was found. Those with parents who abuse alcohol are 28.667 times more likely to abuse alcohol than those whose parents did not abuse alcohol. These finding is incoherent with that of Ndegwa et al. (2013) where ever seeing the mother abuse alcohol had marginal significant association with alcohol intake scores and Roche(2001) who found an association between parents who abstain and children who become heavy drinkers laterin life. The findings are however in line with White, et al., (2000) who found a strong correlation between parental and children's drinking behavior. Many researchers have tried to explain the pattern of alcohol abuse between child and parent. While some studies have taken a genetic approach (Mayfield et.al. 2008; Kendler et al 2003; Windle and Mrug, 2014) in explaining this, others have maintained the learned behavior approach (Sirera and Mwenje 2014; Grekin, et al., 2005). According to White, et al. (2000), children tend to model the drinking patterns and styles of their parents. This seems to be the case in Luanda sub-county. Ndakalu (2014), argues that excessive alcohol abuse, leading to addiction, depletes family finances leading to poverty and these psychosocial depressors then become a predisposing factor towards alcohol abuse by the younger generation. This could also offer another possible explanation of what is occurring in Luanda sub-county. Mwai et al., (2013) observe that adult children of alcoholic parents have lower self esteem and higher odds of becoming alcoholics.

\subsubsection{Spousal alcohol consumption}

A total of $261(64.44 \%)$ respondents were single while $143(35.31 \%)$ were married and $1(0.25 \%)$ were specified as other. Of the married, $58(14.3 \%)$ had spouses who consumed alcohol while $86(21.2 \%)$ had spouse who did not consume alcohol (See Fig. 4.1 below).

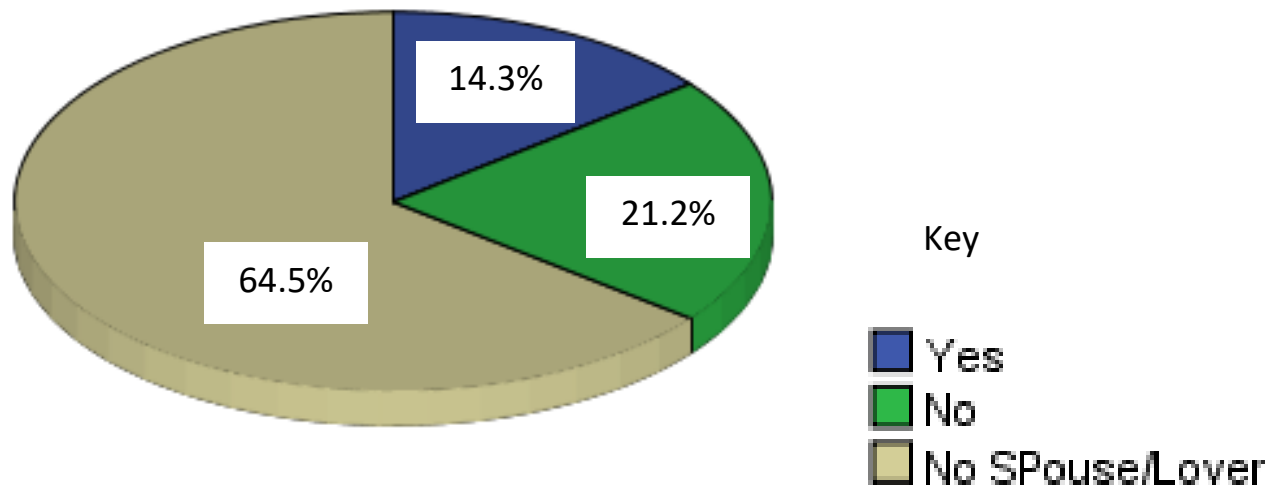

Figure 4.1: Spousal alcohol consumption 
A bivariate analysis of spousal alcohol consumption and the respondents alcohol consumption showed that there was a significant relationship between spousal alcohol consumption and the respondents alcohol abuse. Respondents whose spouses consumed alcohol were 0.462 times less likely to abuse alcohol compared to those whose spouses never abused alcohol. ( $\mathrm{OR}=0.462, \mathrm{CI}=95 \%$ [0.223 -0.955]). Those who had no spouse were 0.834 times less likely to abuse alcohol compared to those whose spouse consumed alcohol OR=0.834 CI=95\% [0.437-1.589]. This could either mean that youth who abused alcohol coupled up with youth who never abused alcohol or abuse of alcohol by one of the spouses discouraged the use of alcohol by the other member of the couple in the relationship. The study however does not conform to a study by Kenneth et. al. (2018) which found out that the risk for alcohol use disorder was substantially increased when the partner had an alcohol use disorder and decreased when the partner did not have an alcohol use disorder.

In this study, those who had no spouse were 0.834 times less likely to abuse alcohol compared to those who were in a relationship and with a spouse who consumed alcohol. This was in agreement with Francis et al (2015) who showed that being in a relationship was associated with alcohol abuse. However, it was in disagreement with O'Connell et al (2013) who found that alcohol abuse is higher in unmarried subjects. Robles and Kiecolt-Glaser (2003) argue that unmarried persons are more likely to engage in alcohol abuse than married ones. This does not seem to be the case in Luanda sub-county. The married person with an alcohol abusing spouse has higher odds of alcohol abuse in Luanda. This could be attributed to other social, cultural and economic factors such as material depressors and psychosocial depressors at play.

\subsubsection{Peer influence}

Respondents were asked if they had any peer in their social group who uses alcohol and whom they spend their time with. A total of 177 (43.7\%) of the respondents spent their time with a friend who consumes alcohol while only 42 $(10.37 \%)$ spent their time alone hence no member of their social group is abusing alcohol. A bivariate analysis of all members of the social groupings against alcohol abuse showed that there was a strong relationship between alcohol abuse and peer influence. A further analysis shows that friendship influence had the greatest association on alcohol abuse (OR=10.012 CI=95\% [3.424-29.273]). This means that those who had friends that abuse alcohol, were ten times more likely to abuse alcohol as compared to those who did not. Studies by Takahashi et. al (2017) and Ngesu et al (2008) are generally in agreement with these findings.

Peer pressure has been linked to alcohol abuse either as misconduct by the youth, need for peer involvement and need for peer conformity. (Studer et al., 2014). YohannesBisaBiramo and GedionPhilipos (2016) note that peer pressure enables the setting of norms of behavior and normally it develop a 
culture that manifests itself in aspects like language, dress, hairstyle, sports, and drinking habits. In Luanda sub-county, this seems the case, whereby youth have influence over other youth and thereby leading to peer influence on alcohol abuse.

Table 4.10: Bivariate analysis: Associated socio-cultural factors of alcohol abuse

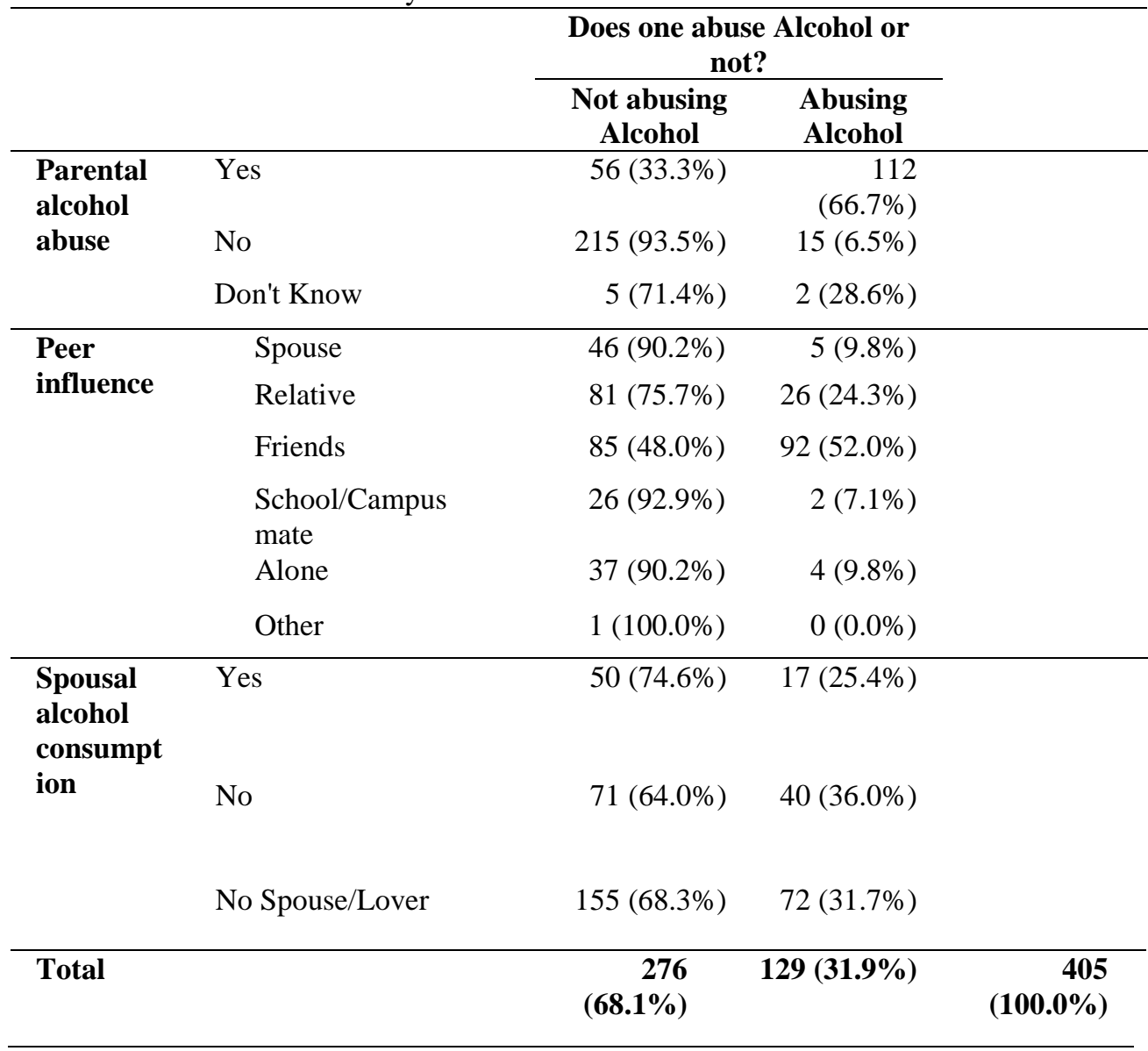




\subsubsection{Cultural practices when alcohol is abused}

Customs and cultural expectations were of less importance as factors of alcohol abuse. A total of 247 (61.0\%) respondents indicated that cultural expectations did not at all influence alcohol abuse. Only 24 (5.9\%) indicated that customs largely influenced alcohol abuse to a great extent with $1(0.2 \%)$ indicating a very great extent of influence. Respondents were queried on cultural circumstances likely to encourage alcohol abuse. Alcohol was noted to be of importance in several cultural practices where its abuse among the youth would easily occur. Parties 77 (44.0\%) which would be held in the community by youth generally regarded as 'bash' were the instances when alcohol abuse would occur highest in a cultural context (See Figure 4). From the FGD, it was deduced that most parties would be held to celebrate mostly a birthday party, a meeting, a get-well soon, a home coming, end of year or a finish of school event. Funerals 52 (29.7\%) were also a point of cultural-based alcohol abuse as it was reported that the youth would get intoxicated to enjoy the night away and keep vigil during funerals, a phenomenon termed as 'disco matanga'. Among the listed cultural celebrations, alcohol was least abused in circumcision ceremonies $12(6.9 \%)$ by youth (Figure 4). Other $8(4.6 \%)$ named cultural celebrations where alcohol was abused included celebration of the newborns and success in social issues such as passing annual national exams and graduations. (Figure 4).

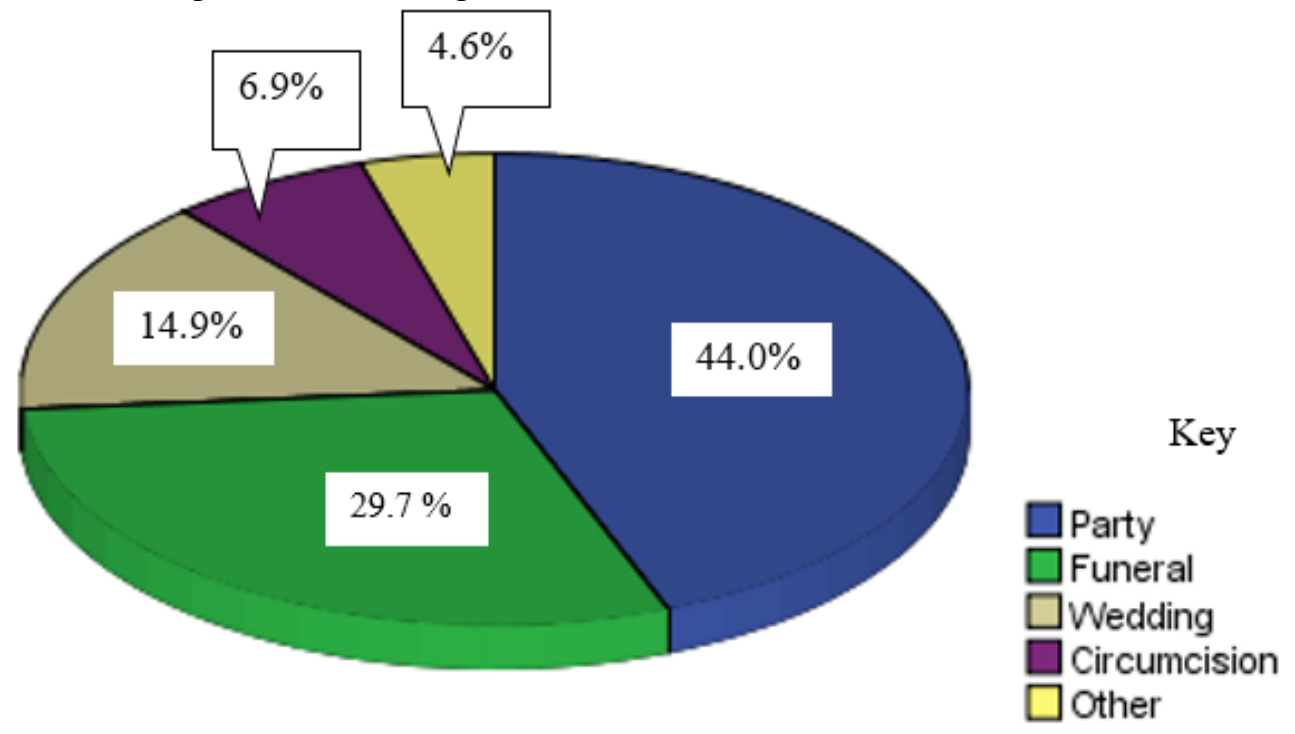

Figure 4: Cultural practices when alcohol is abused

From the FGD, it was deduced that parents were the immediate custodians of customs in Luanda sub-county among the predominant Wanyore people and would thus highly influence their children's alcohol use tendencies, as recognized by respondents. 
During the FGD, it was also found out that use of alcohol by the youth was generally abhorred. Customs was noted as the least important causative of alcohol abuse among the youth has been noted.

This is divergent from the findings of Keiwua (2016) who found that $59.2 \%$ of the respondents said cultural beliefs and practices advance alcohol abuse and NACADA (2007) found out that the decision to drink by both adults and young people is motivated by a variety of factors, such as cultural acceptability of alcohol.

From the findings of the study, it was also clear from respondents who abused alcohol that they were likely to do so during customary celebrations such as parties (bash) and funeral night vigils (disco matanga). Among the listed cultural celebrations, alcohol was least abused in circumcision ceremonies. This findings were different from those of Keiwua (2016) where $(80 \%)$ of the teachers indicated initiation ceremonies as the main cultural practice that advance usage of alcohol by students in Maasai community.

These differences could be showing some cultural differences between the expectations of new initiate among the Maasai and the Anyole (Luhya) people.

From the FGD, there is no explicit custom that encourages the youth to use alcohol in the society. Instead, there is a general feeling that it is disrespectful to the head of the household to utilize alcohol while still under their care. The customs abhor alcohol abuse among the youth unless for specific cultural reasons; in which a senior authority within the society oversees the process.

\section{Conclusion}

The study established that alcohol abuse in Luanda sub-county is significantly positively associated with parental alcohol consumption. Those with alcohol consuming parents are more likely to abuse alcohol than those whose parents did not consume alcohol. The study further revealed that there aresignificant negative relationships between spousal alcohol consumption and the respondent's alcohol abuse status among youth in Luanda sub-county. Respondents whose spouses consumed alcohol were less likely to abuse alcohol. Further, the study established a strong relationship between alcohol abuse and peer influence. Those who kept friends that consume alcohol, were ten times more likely to abuse alcohol as compared to those who did not. However, in the study, customs and cultural expectations were of less importance as factors of alcohol abuse among youth in Luanda sub-county. Overall, socio-cultural factors are highly associated with alcohol abuse among youth in Luanda Sub-county.

It is necessary that societal pressure groups increase awareness campaigns on effect of parental alcohol use on youth in Luanda sub-county so 
as to reduce alcohol abuse. It is also recommended that there is a need to come up with modalities that will strengthen the cultural aspects that abhor alcohol abuse.

It is recommended that all stakeholders need to step up the eradication of unemployment among the youth in Luanda sub-county. For those in universities and colleges, there is need to getting them into activities that will ensure a productive use of their time; whenever they are off class work. It is also recommended that there is need to financially empower the youth in Luanda sub-county to help reduce alcohol abuse.

\section{References:}

1. Aisha, I. M., Ashraf, M. E., Enas, I. E.-M., \& Mennat-Allah, A. M. E.R. (2012). Pedriatric Poisoning in Egypt. Journal of applied pharmaceutical science, 2(2), 1-6.

2. Arulmurugan, C., Ahmed, S., \& Gani, M. (2015). A retrospective study of paradigm and outcome of acute poisoning cases in a tertiary care teaching hospital in Southern India. International Journal of Research in Medical Sciences, 2654-2657. https://doi.org/10.18203/2320-6012.ijrms20150808

3. CDC. (2020). Venomous Snakes: Types of Venomous Snakes. U.S. Department of Health \& Human Services. Retrieved 22nd August from https://www.cdc.gov/niosh/topics/snakes/types.html

4. Chen, F., Wen, J.-p., Wang, X.-p., Lin, Q.-m., \& Lin, C.-j. (2010). Epidemiology and characteristics of acute poisoning treated at an emergency center. World journal of emergency medicine, l(2), 154.

5. Chien, W.-C., Lin, J.-D., Lai, C.-H., Chung, C.-H., \& Hung, Y.-C. (2011). Trends in poisoning hospitalization and mortality in Taiwan, 1999-2008: a retrospective analysis. BMC Public Health, 11(1), 703.

6. Connolly, G. N., Richter, P., Aleguas, A., Jr., Pechacek, T. F., Stanfill, S. B., \& Alpert, H. R. (2010). Unintentional child poisonings through ingestion of conventional and novel tobacco products. Pediatrics, 125(5), 896-899. https://doi.org/10.1542/peds.2009-2835

7. Eslami, M., Kousha, S., Fesharaki, M., Kazemi, N., Ghafarzad, A., Zamani, M., \& Nia, K. S. (2014). Evaluation prevalence and causes of drug and chemical poisoning in patients referred to emergency wards of Sina Hospital of Tabriz University of Medical Sciences at 2012-13. Int J Curr Res Aca Rev, 2, 187-194.

8. Griego, R. D., Rosen, T., Orengo, I. F., \& Wolf, J. E. (1995). Dog, cat, and human bites: a review. Journal of the American Academy of Dermatology, 33(6), 1019-1029.

9. Gummin D.D., James B. Mowry, Michael C. Beuhler, Daniel A. Spyker, Daniel E. Brooks, Katherine W. Dibert, Laura J. Rivers, 
Nathaniel P. T. Pham \& Mark L. Ryan (2020) 2019 Annual Report of the American Association of Poison Control Centers' National Poison Data System (NPDS): 37th Annual Report, Clinical Toxicology, 58:12, 13601541, DOI: $10.1080 / 15563650.2020 .1834219$

10. Imoudu, I., Afegbua, D., Elike, M., Ishola, I., \& Abubakar, A. (2018). Acute Childhood Poisoning in Azare North Eastern Nigeria. Journal of Advances in Medicine and Medical Research, 26(3), 1-8. https://doi.org/10.9734/jammr/2018/41050

11. Jeyaratnam, J. (1990). Acute pesticide poisoning: A major global health problem. Wld. Hlth. Statist. Quart., 43, 139-144.

12. Kenko, N., Fai, P., Ngameni, T., \& Mpoame, M. (2017). Environmental and Human Health Assessment in Relation to Pesticide Use by Local Farmers and the Cameroon Development Corporation (CDC), Fako Division, South-West Cameroon. European Scientific $\begin{array}{lllll}\text { Journal, } & \text { ESJ, } & \text { 13(21), } & 454 & -\end{array}$ https://doi.org/10.19044/esj.2017.v13n21p454

13. Kenko, N. D. B. (2020). Pesticide Risk Assessment and Study of the Phytoplankton Community for the Biomonitoring of the Benoe Stream, South-West Cameroon PhD Thesis, Department of Animal Biology, University of Dschang, p.150.]. Cameroon.

14. Kenko, N. D. B., Fai, P. B. A., Tasse, T. G. C., Ngameni, T. N., Ngealekeleoh, F., \& Mpoame, M. (2017). Assessment of chemical pollution with routine pesticides using PRIMET, a pesticide risk model in the Benoe stream in the South-West Region of Cameroon. Eur Sci $J, 13(30), 153-172$.

15. Kenko, N. D. B., Ngwe, B. M. U., \& Ngameni, T. N. (2020). Five year (2013-2017) trends in poisoning among patients of the Buea Regional Hospital, South-West Region (Cameroon). Brazilian Journal of Biological Sciences, 7(16), 209-216. https://doi.org/https://doi.org/10.21472/bjbs(2020)071607

16. Liisanantti, J. (2012). Acute drug poisoning: outcome and factors affecting outcome (Publication Number 1154) University of Oulu Graduate School]. Oulu, Finland.

17. Loughlin, F. (2020). Understanding the long-term effects of dog bite injuries. Retrieved 22nd August from https://www.lflaw.com/understanding-the-long-term-effects-of-dogbite-injuries/

18. Maharani, B., \& Vijayakumari, N. (2013). Profile of poisoning cases in a Tertiary care Hospital, Tamil Nadu, India. Journal of applied pharmaceutical science, 3(1), 91. 
19. Mahdi, B.-M., \& Mohammad, A. (2014). Basic and Clinical Toxicology of Organophosphorus Compounds. Springer-Verlag https://doi.org/10.1007/978-1-4471-5625-3

20. Manfo, F. P. T., Moundipa, P. F., Déchaud, H., Tchana, A. N., Nantia, E. A., Zabot, M. T., \& Pugeat, M. (2012). Effect of agropesticides use on male reproductive function: a study on farmers in Djutitsa (Cameroon). Environmental toxicology, 27(7), 423-432.

21. Mas-Morey, P., Visser, M. H. M., Winkelmolen, L., \& Touw, D. J. (2012). Clinical Toxicology and Management of Intoxications With Synthetic Cathinones ("Bath Salts"). Journal of Pharmacy Practice, 26(4), 353-357. https://doi.org/10.1177/0897190012465949

22. Moazzam, M., Al-Saigul, A., Naguib, M., \& Al Alfi, M. (2009). Pattern of acute poisoning in Al-Qassim region: a surveillance report from Saudi Arabia, 1999-2003. Eastern Mediterranean Health Journal, 15(4), 1005-1010.

23. Morris, C., Savy, C., Judge , S., \& Blain, P. (2014). Acute Toxicity of Organophosphorus Compounds. In B. Mahdi \& A. Mohammad (Eds.), Basic and Clinical Toxicology of Organophosphorus Compounds (pp. 45-78). Springer. https://doi.org/DOI 10.1007/978-1-4471-5625-3

24. Oreby, M., Maklad, A., Shihab, N., \& Kassem, H. (2016). Prediction of Outcome of Acutely Intoxicated Patients Admitted To Intensive Care Unit in Mansoura-Dakhlia Governorate-Egypt. Ain Shams Journal of Forensic Medicine and Clinical Toxicology, 26(1), 140150.

25. Ramazan, Ö., Benan, B., Özlem, T., Bilgehan, Y., \& Gülsev, K. (2012). Thirty-three-year experience on childhood poisoning. The Turkish Journal of Pediatrics, 54, 251-259.

26. Saravi, B. M. (2013). Prevalence of Non-drug Poisoning in Patients Admitted to Hospitals of Mazandaran University of Medical Sciences, 2010-2011. Acta informatica medica, 21(3), 192.

27. Sinicropi, M. S., Amantea, D., Caruso, A., \& Saturnino, C. (2010). Chemical and biological properties of toxic metals and use of chelating agents for the pharmacological treatment of metal poisoning. Arch Toxicol, 84(7), 501-520. https://doi.org/10.1007/s00204-010-0544-6

28. Sonchieu, J., Azouline, M., \& Ngassoum, B. M. (2018). Investigation on Five Years (2010-2014) Food Poisonings Recorded in Bamenda and Ndop Public Hospitals, Cameroon. Health Science and Disease, 19(3), 100-106.

29. Tejas, P., Kartik, P., Rakesh, T., \& Saumil, M. (2013). Acute Chemical and Pharmaceutical Poisoning Cases Treated in Civil Hospital, Ahmedabad: One year study. ASIA PACIFIC JOURNAL of MEDICAL TOXICOLOGY, 2(2), 63-67. 
30. Tsalkidis, A., Vaos, G., Gardikis, S., Kambouri, K., Tripsianis, G., Mantadakis, E., Paraskakis, E., \& Chatzimicael, A. (2010). Acute Poisoning among Children Admitted to a Regional University Hospital in Northern Greece. Central European journal of public health, 18(4), 219-223. https://doi.org/10.21101/cejph.a3617

31. Uges, D. (2001). What is the definition of a poisoning? Journal of Clinical Forensic Medicine, 8(1), 30 - 33. https://doi.org/https://doi.org/10.1054/jcfm.2000.0465

32. Viau, C., \& Tardif, R. (2003). Toxicologie. In M. Gérin, P. Gosselin, S. Cordier, C. Viau, P. Quénel, \& E. Dewailly (Eds.), Environnement et santé publique : Fondements et Pratiques (pp. 119-143). Edisem.

33. WHO. (2019). Suicide. World Health Organization. Retrieved 22nd August 2020 from https://www.who.int/news-room/factsheets/detail/suicide

34. WHO. (2020a). Environmental health in emergencies: poisoning. World Health Organization. Retrieved 20th August from https://www.who.int/environmental_health_emergencies/poisoning/e $\mathrm{n} /$

35. WHO. (2020b). Health Topics : Snakebite Envenoming. World Health Organization. Retrieved 22nd August from https://www.who.int/health-topics/snakebite\#tab=tab_1

36. Zardosht, M., Dastoorpoor, M., Hashemi, F. B., Estebsari, F., Jamshidi, E., Abbasi-Ghahramanloo, A., \& Khazaeli, P. (2016). Prevalence and Causes of Self Medication among Medical Students of Kerman University of Medical Sciences, Kerman, Iran. Global Journal of Health Science, 8(11), 150. https://doi.org/10.5539/gjhs.v8n11p150

37. Zeinab, A. E. A.-E., \& Badar, A. A. M. (2014). Pattern of acute poisoning in Al Majmaah region, Saudi Arabia. American Journal of Clinical and Experimental Medicine, 2(4), 79-85. https://doi.org/10.11648/j.ajcem.20140204.15 